\title{
A new methodology to obtain the fracture toughness of YAG transparent ceramics
}

\author{
Haomin $\mathrm{WANG}^{a}$, Zhangyi $\mathrm{HUANG}^{b}$, Jianqi QI ${ }^{b, c}$, Jun $\mathrm{WANG}^{d, *}$ \\ ${ }^{a}$ Institute for Advanced Study, Chengdu University, Chengdu 610106, China \\ ${ }^{b}$ College of Physical Science and Technology, Sichuan University, Chengdu 610064, China \\ ${ }^{c}$ Key Laboratory of High Energy Density Physics and Technology of Ministry of \\ Education, Sichuan University, Chengdu 610064, China \\ ${ }^{d}$ School of Physics and Electronic Engineering, Sichuan University of \\ Science \& Engineering, Zigong 643000, China
}

Received: November 16, 2018; Revised: March 4, 2019; Accepted: March 9, 2019

(C) The Author(s) 2019.

\begin{abstract}
A new methodology was proposed for testing the fracture toughness of YAG transparent ceramics depended on temperature. In our model, the fracture toughness, as a material-specific property, can be expressed as tensile strength treated as the physical property or a material constant. Using this method, a suitable size larger than the inherent defects of ceramic samples and the creation of atomically sharp pre-cracks on the surface of ceramic specimens were able to be ignored. Besides, the fracture of ceramic can be described as the equivalence between the release of elastic storage energy and surface energy associated with the new fracture surface. From thermodynamics theory, the system's internal energy includes the kinetic energy of atomic motion and the potential energy between atoms in the system. Finally, the fracture toughness at different temperatures can also be calculated by this simple quantitative relationship. In order to confirm the validity of this model, the decreasing fracture toughness of YAG transparent ceramic with increasing temperature was predicted, and the result coincided with the experimental results.
\end{abstract}

Keywords: fracture toughness; fracture strength; transparent ceramic; high temperature; YAG ceramic

\section{Introduction}

Yttrium aluminum garnet $\left(\mathrm{Y}_{3} \mathrm{Al}_{5} \mathrm{O}_{12}, \mathrm{YAG}\right)$ transparent ceramic has recently acquired a high degree of interest. The most important applications of YAG transparent ceramics include the high power solid state laser materials and high-temperature optical windows, etc. [1-5]. For such applications, materials must have good

* Corresponding author.

E-mail: wangjun@suse.edu.cn mechanical characteristics to ensure high reliability during service [6-10]. Currently, the most accepted concepts pertaining to the mechanics of failure of solid matter are established by the field of fracture mechanics. The fundamentals of such concepts revolve around the idea that discontinuities (flaws, voids, defects, cracks) in a material, which are on the surface or in the bulk, act as stress concentration entities from which failure will begin and grow to catastrophic fracture [11,12]. Among all of the mechanical properties of ceramic materials, fracture toughness $\left(K_{\mathrm{IC}}\right)$ 
is an intrinsic material property that is known as the critical stress intensity factor at which a crack of a given size starts to grow in an unstable manner under plane strain conditions and opening mode loading (mode I). As brittle materials mostly fail in mode I, and $K_{\mathrm{IC}}$ is of significant importance in evaluating the brittleness of ceramic materials and its determination has long been a hotspot [11-15]. Therefore, the investigation of the relationship between fracture toughness of YAG transparent ceramic and temperature will be significant for engineering applications. To the best of our knowledge, conventional testing methods such as compact tension (CT), double cantilever beam (DCB), chevron notched beam (CNB), double cleavage drilled compression (DCDC), double torsion (DT), edge "V" notch beam (SEVNB) or single-edged precracked beams (SEPB) in bending, and indentation methods (IF) are commonly used for advanced ceramic materials to measure $K_{\mathrm{IC}}$ value [16-21].

Generally speaking, what sets apart the testing of fracture toughness from the testing of strength is the presence of an artificially introduced crack, having a well-defined geometry and measurable dimensions. Under an applied external load the stress intensity factor at the crack tip is proportional to the global stress state in the specimen and to the square root of the crack length [22-25]. The recommended methods for $K_{\mathrm{IC}}$ of advanced ceramics were the SEPB, SEVNB, and IF due to their small grain size of about few microns [26-40]. The main advantage of SEVNB is the ease of producing the notch via a cutting disk. The SEPB test uses the traditional configuration of uniaxial flexural strength method and provides results with good accuracy. However, both of the two methods commonly required an ideal artificial sharp crack which is difficult to obtain, while a relatively simple man-made notch will arouse significant test error. Moreover, according to the ASTM standard (ASTM 1990) for $K_{\mathrm{IC}}$ measurement of ceramic materials, a crack has to be longer than $2.5\left(\frac{K_{\mathrm{IC}}}{\sigma_{y}}\right)^{2} \quad\left(\sigma_{y}\right.$ is fracture strength) for ceramic can be considered as homogeneous, plane strain state and unstable propagation of the crack. Thus, the IF method became very popular in the advanced ceramic materials field due to its non-destructive nature and simplicity. But it has been shown that when comparing $K_{\mathrm{IC}}$ results obtained by the IF method with those obtained by other methods that use some sort of pre-crack, there is only about $30 \%$ agreement of results. This is due to the complicated stress state near the indented crack.

Furthermore, ceramic materials are potential candidates for use in high-temperature condition, but the fracture properties containing $K_{\mathrm{IC}}$ at high temperature are very difficult to obtain via these testing methods as mentioned above. So in this work, we will want to propose a simple methodology to obtain the fracture toughness of YAG transparent ceramic at different temperatures.

\section{Experimental procedure}

\section{1 YAG transparent ceramic preparation}

Yttrium nitrate $\left(\mathrm{Y}\left(\mathrm{NO}_{3}\right)_{3} \cdot 6 \mathrm{H}_{2} \mathrm{O}, 99.99 \%\right)$ and ammonium aluminum sulfate $\left(\mathrm{NH}_{4} \mathrm{Al}\left(\mathrm{SO}_{4}\right)_{2} \cdot 12 \mathrm{H}_{2} \mathrm{O}, 99.99 \%\right)$ were mixed according to the stoichiometric ratio of YAG in deionized water. The precipitant solution was prepared by dissolving ammonium hydrogen carbonate $\left(\mathrm{NH}_{4} \mathrm{HCO}_{3}\right.$, analytical grade) in a mixed solvent of alcohol and distilled water. The mixed solution was dripped into the precipitant solution. After aged for $20 \mathrm{~h}$, the suspension was filtered and washed with distilled water and alcohol, and the precipitate was finally obtained. Then precursors were produced after the precipitate was dried at $80{ }^{\circ} \mathrm{C}$ for $24 \mathrm{~h}$ in an oven. The obtained precursors were calcined at $1100{ }^{\circ} \mathrm{C}$ in order to produce the YAG powders. The YAG powders were uniaxially pressed into pellets at a pressure of $20 \mathrm{MPa}$ and then isostatically cold pressed at $200 \mathrm{MPa}$ to obtain green bodies. The green bodies were sintered at $1780{ }^{\circ} \mathrm{C}$ for $20 \mathrm{~h}$ in a high-temperature vacuum sintering furnace under a vacuum condition of $10^{-3} \mathrm{~Pa}$. The heating and cooling rates were both set to $10{ }^{\circ} \mathrm{C} / \mathrm{min}$. Subsequently, sintered pellets were annealed at $1450{ }^{\circ} \mathrm{C}$ for $20 \mathrm{~h}$ in air and the YAG transparent ceramic samples were obtained. Finally, the YAG transparent ceramic samples were cut to beam specimens with $3 \mathrm{~mm} \times 4 \mathrm{~mm} \times 36 \mathrm{~mm}$. And all of the surfaces of these beam specimens were polished with high quality.

\section{2 Characterization of materials}

The phase and crystallinity were analyzed via X-ray diffraction (XRD, $\mathrm{Cu} \mathrm{K \alpha}$ radiation, $1.54 \AA$, Model $\mathrm{D} / \mathrm{max} 2000 \mathrm{PC}$, Rigaku, Japan) in the $2 \theta$ range from $10^{\circ}$ to $80^{\circ}$. The grain size and microstructures of the 
YAG transparent ceramics were investigated by scanning electron microscopy (SEM, Model S-4800, Hitachi, Japan) combining with electron back-scattered diffraction (EBSD) at the acceleration voltage of $15 \mathrm{kV}$, the beam intensity of $15 \mathrm{~mA}$, and the tilt angle of $70^{\circ}$. In addition, the resolution of EBSD is about $30 \mathrm{~nm}$. Besides, the scanning step and time step were $150 \mathrm{~nm}$ and $20.2 \mathrm{~ms}$, respectively. The EBSD results were processed by CHANNEL 5 software (HKL Technology, Inc., UK). Noise reduction was carried out with level 5. The polished surface morphology of YAG sample was observed by atomic force microscopy (AFM, MFP-3DBIO, Asylum Research, USA). The relationship between the elastic modulus of YAG and the temperature was measured by using the dynamic resonance method (Model RFDA MF System21, Choukou Trading Co., Japan). A universal testing machine (Model 5866, Instron Corp., Norwood, MA, USA) was employed to determine fracture strength at the reference temperature (room temperature) using three-point bending specimens with beam size $3 \mathrm{~mm} \times 4 \mathrm{~mm} \times 36 \mathrm{~mm}$ with $30 \mathrm{~mm}$ span width at a loading rate of $0.5 \mathrm{~mm} / \mathrm{min}$.

\section{Modelling}

Actually, the use of strength specimens having natural flaws and no artificially introduced crack for the calculation of $K_{\mathrm{IC}}$ is a valid method as far as the theory goes, but it was not made into an official standard for fracture toughness testing due to practical issues. It can be attributed to that the crack dimensions have to be obtained fractographically due to the small size of the defects (in ceramics these are usually pores, badly sintered regions, microstructural heterogeneities, or surface/corner defects introduced during preparation [41-45]), usually requiring a scanning electron microscope and experience to interpret fracture markings [46]. Even the origin is clear, in most cases strength controlling defects have no defined shape, requiring a rough estimation of the value of geometric factors. These lead to a high scatter in fracture toughness values, along with the fact that, from a set of strength specimens, initiating defects can be of different nature, requiring varying geometric factors.

It is well known that the fracture behaviors of materials are controlled by the perfect elastic, perfect plastic, and elastic/plastic fracture criteria. Also, the perfect plastic failure is dominated by the tensile yield strength $\sigma_{\mathrm{y}}$ and the perfect elastic fracture criterion associated with the plane strain fracture toughness $K_{\mathrm{IC}}$. For example, the tensile failure of a plate specimen with an edge crack is shown in Fig. 1(a). The fracture model is dependent on the edge crack and the size of the specimen. For a large enough length of the edge crack the failure can be seen as a perfect elastic fracture. Insteadly the fracture behavior was controlled by the perfect plastic criterion. As shown in Fig. 1(b) both the two fracture criteria are exhibited. We can find a critical crack size which bridges the two different criteria. However, all of the fracture behaviors should be treated as elastic/plastic fracture failure, and occur at the cross region shown in Fig. 1(b). So we can conclude that the compact correlations between the tensile yield strength and the fracture toughness exist. Also, the gap between the tensile strength and fracture toughness can be bridged by the critical crack size.

Let's look back to the testing of fracture toughness from the testing of strength. The errors of fracture toughness originated from the geometry factor and fracture strength associated with the unstable fracture. But the fracture toughness, as a material-specific property, should arrive in the same value irrespective of testing strategy. Namely, if we can find a relationship between the fracture toughness and the other material-specific property which can be measured conveniently and accurately, the fracture toughness will be calculated without difficulty.

Zhang et al. [47] developed a model for size effect in quasi brittle materials, which contained a characteristic crack $a^{*}$ :

$$
a^{*}=0.25\left(\frac{K_{\mathrm{IC}}}{\sigma_{\mathrm{y}}}\right)^{2}
$$

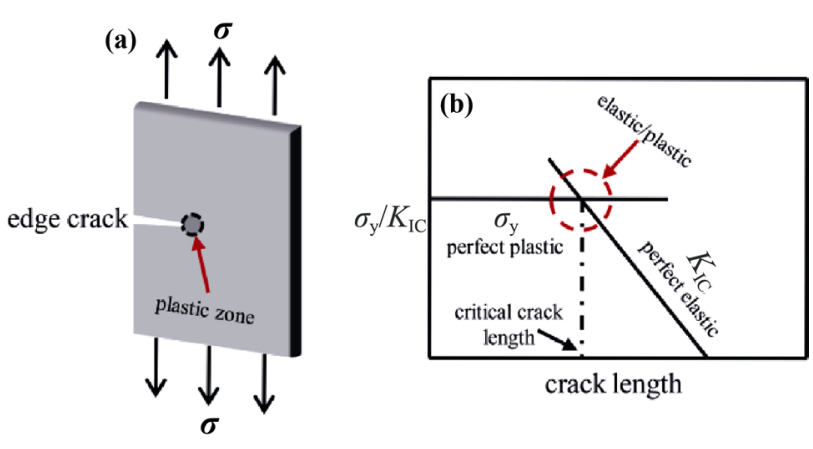

Fig. 1 (a) Tensile plate specimen fracture failure with edge crack, and (b) the two different fracture criteria associated with tensile yield strength $\sigma_{\mathrm{y}}$ and the plane strain fracture toughness $K_{\mathrm{IC}}$. 
where $\sigma_{\mathrm{y}}$ is the tensile strength. This characteristic crack $a^{*}$ represents the intersection of perfect elasticplastic and ideal linear elastic fracture criteria. In the region where $a=a^{*}$ fracture occurs at a combination of elastic and plastic fracture. The true failure curve should approach asymptotically to both the pure elastic and plastic criteria under the condition $a \gg a^{*}$ and $a \ll a^{*}$. Significantly, there is an inherent relation between the microstructure and bulk material properties such as the tensile strength $\sigma_{\mathrm{y}}$ and fracture toughness $K_{\mathrm{IC}}$. So, Hu and Wittmann [48] considered that the tensile strength $\sigma_{\mathrm{y}}$ can be obtained by a simple fracture mechanics model after assuming the relative characteristic crack $\frac{a^{*}}{G}=C$, where $G$ is the average grain size in advanced ceramic and $C$ is a constant. Ceramic samples with shallow surface cracks with size $a$ under bending condition illustrated in Fig. 6(a) can be given by

$$
\sigma_{\mathrm{y}}=\sigma_{\mathrm{N}} \sqrt{1+\frac{a}{C G}}
$$

where $\sigma_{\mathrm{N}}$ is the fracture strength in bending condition. Equations (1) and (2) can be conveniently combined into one formula of fracture toughness $K_{\mathrm{IC}}$ :

$$
K_{\mathrm{IC}}=2 \sigma_{\mathrm{N}} \sqrt{a+C G}
$$

In Eq. (3), the fracture toughness $K_{\mathrm{IC}}$ can be bridged with the tensile strength $\sigma_{\mathrm{y}}$ (or the fracture strength $\left.\sigma_{\mathrm{N}}\right)$. Significantly, when the surfaces are the perfect planes without shallow surface cracks the tensile strength is coincide with the fracture strength. Moreover, the fracture toughness $K_{\mathrm{IC}}=2 \sqrt{C G} \sigma_{\mathrm{N}}=2 \sqrt{C G} \sigma_{\mathrm{y}}$. However, even highly polished surfaces maintain nonnegligible roughness at small scales, and the defects or shallow surface cracks inevitably emerge on the surfaces of testing specimens. On the other hand, there are usually residual pores, second phases, and other micro defects inside ceramics introduced during preparation. As is well known, the tensile strength can be treated as the physical property or a material constant, so its variation in experimental measurements should follow the normal distribution. So we can conclude that under the condition of the perfect surface, the normal distribution of ceramic tensile strength is originated from the random distribution of internal defects in ceramic. In Hu and Wittmann's work, the tensile strength measurements of four different ceramics with different grain sizes were analyzed. For a given $C \approx 3.0$, the

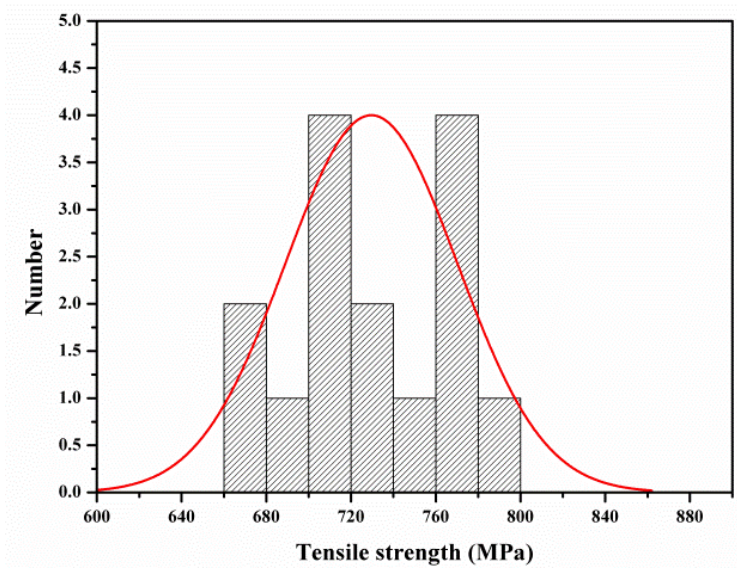

Fig. 2 Number of specimens and normal distribution of tensile strength of $\mathrm{Si}_{3} \mathrm{~N}_{4}$ in Kimoto et al. [50].

tensile strength results calculated from fracture strength (using Eq. (2)) can be analyzed using the standard normal distribution. According to Eq. (3), we can see the fracture toughness of ceramic should also obey the normal distribution. This result is coincident with the inherent property of fracture toughness as a materialspecific property. The use of strength specimens having natural flaws and no artificially introduced crack for the calculation of $K_{\mathrm{IC}}$ is a valid method as far as the theory goes. So in this methodology, we can firstly measure the tensile strength of ceramic specimens with natural surface defects, and then calculate their fracture toughness values using Eq. (3).

From the above formula (Eq. (3)), a simple quantitative relationship is revealed between fracture toughness, fracture strength, and average grain size. Significantly, the influence of temperature on the fracture toughness can be tactfully considered in the fracture strength. From thermodynamics theory, the system's internal energy includes the kinetic energy of atomic motion and the potential energy between atoms in the system. Besides, the fracture of ceramic can be described as the equivalence between the release of elastic storage energy and surface energy associated with the new fracture surface. Deng et al. [49] assumed there is a maximum storage energy density, which is associated with the onset of material failure and independent on temperature. In an isothermal process, the quantitative relationship between the fracture strength and temperature can be expressed as

$$
\sigma_{\mathrm{N}}(T)=\sigma_{\mathrm{N}}\left(T_{0}\right)\left[\frac{E(T)}{E\left(T_{0}\right)} \times \frac{T_{\mathrm{m}}-T}{T_{\mathrm{m}}-T_{0}}\right]^{\frac{1}{2}}
$$


where $\sigma_{\mathrm{N}}(T)$ and $E(T)$ are the fracture strength and Young's modulus at temperature $T$ respectively, $\sigma_{\mathrm{N}}\left(T_{0}\right)$ is the fracture strength at a reference temperature $T_{0}$, and $T_{\mathrm{m}}$ is the melting point of the ceramic materials. So, the fracture toughness $K_{\mathrm{IC}}(T)$ at temperature $T$ can be described as

$$
K_{\mathrm{IC}}(T)=2 \sigma_{\mathrm{N}}\left(T_{0}\right)\left[\frac{E(T)}{E\left(T_{0}\right)} \times \frac{T_{\mathrm{m}}-T}{T_{\mathrm{m}}-T_{0}}\right]^{\frac{1}{2}} \cdot \sqrt{a+C G}
$$

\section{Results and discussion}

For the validity of this methodology, the testing results from some references were firstly employed to calculate the fracture toughness at room temperature. In 1985, Kimoto et al. [50] investigated the relationship between fracture strength and flaw size in different ceramic materials. In their work, the $\mathrm{Si}_{3} \mathrm{~N}_{4}$ ceramics with an average grain size of $3 \mu \mathrm{m}$ were fabricated using hot press sintering method. The hardness and density of these specimens were $H_{\mathrm{v}}(4.9 \mathrm{~N})=13 \mathrm{GPa}, \rho=3.2$ $\mathrm{g} \cdot \mathrm{cm}^{-3}$, respectively. All of the artificial cracks or flaws with different sizes were prepared using diamond wheels, Vickers indented method, and abrasive papers. The measured pre-cracked sizes $a$, fracture strength $\sigma_{\mathrm{N}}$, and the calculated tensile strength $\sigma_{\mathrm{y}}$ are listed in Table 1. We can find that the fracture strength decreased rapidly with increasing crack size, but the tensile strength calculated from Eq. (2) showed a fluctuation around the average value. This indicates that the tensile strength of the advanced ceramic, as a material-specific property, has the same value irrespective of testing strategy. As shown in Fig. 2, considering the normal distribution of the tensile strength, its average value can be found to be 738.6 MPa. Then, using Eq. (3) we can calculate the fracture toughness, $K_{\mathrm{IC}}=4.43 \mathrm{MPa} \cdot \mathrm{m}^{1 / 2}$. After near 30 years, Zhao et al. [51] fabricated an ultra-sharp V-notch with a radius near $0.5 \mu \mathrm{m}$ on the surface of hot press sintered $\mathrm{Si}_{3} \mathrm{~N}_{4}$ ceramic with an average grain size of $1 \mu \mathrm{m}$ and density of $3.24 \mathrm{~g} \cdot \mathrm{cm}^{-3}$. The measured fracture toughness, $K_{\mathrm{IC}}=5.05 \mathrm{MPa} \cdot \mathrm{m}^{1 / 2}$, was tested using the SEVNB method. It looks that there is a little difference between these two values of fracture toughness. But if we can have a further analysis of raw testing data, the fracture strength of $\mathrm{Si}_{3} \mathrm{~N}_{4}$ ceramic samples sintered by Zhao et al. is $848 \pm 75 \mathrm{MPa}$, which is higher than that
Table $1 \quad \mathrm{Si}_{3} \mathrm{~N}_{4}$ ceramic results digitized from Kimoto et al. [50] and our model

\begin{tabular}{ccc}
\hline Crack size $a(\mu \mathrm{m})^{*}$ & $\begin{array}{c}\text { Fracture strength } \\
\sigma_{\mathbf{N}}(\mathrm{MPa}) *\end{array}$ & $\begin{array}{c}\text { Tensile } \\
\text { strength } \sigma_{\mathbf{Y}}(\mathrm{MPa})\end{array}$ \\
\hline 0.099 & 717.9 & 721.8 \\
0.794 & 623.4 & 660.5 \\
3.465 & 662.1 & 779.3 \\
7.187 & 525.4 & 704.6 \\
12.67 & 458.9 & 712.2 \\
22.89 & 362.3 & 681.9 \\
34.83 & 306.2 & 675.6 \\
42.10 & 304.7 & 726.1 \\
63.88 & 249.4 & 709.6 \\
99.06 & 206.3 & 715.0 \\
131.4 & 194.9 & 769.6 \\
149.2 & 186.8 & 783.3 \\
181.2 & 167.4 & 769.5 \\
205.7 & 155.4 & 759.2 \\
226.6 & 151.7 & 776.0 \\
\hline$*$ From Ref. $[50]$ & & \\
$\sigma_{\text {Yavg }}=738.6 \mathrm{MPa}$ from normal distribution, $K_{\mathrm{IC}}=4.35 \mathrm{MPa} \cdot \mathrm{m}^{1 / 2}$ from Eq. $(3)$
\end{tabular}

from Kimoto et al. Thus, this little discrepancy can be attributed to the different microstructures and the imperfect pre-crack.

As mentioned before, using the proposed temperaturedependent fracture toughness model (Eq. (5)), the fracture toughness of YAG transparent ceramics at different temperatures can be obtained. In this paper, YAG transparent ceramic specimens were prepared by vacuum sintering method. The sintered compacts and powders of YAG ceramic were measured and analyzed by XRD. Figure 3 shows the XRD patterns of YAG powders and transparent ceramic specimens. There is only one phase of YAG (JCPDS No. 33-0040) can be observed in these XRD peaks, comparing the XRD patterns with standard JCPDS cards. The transmittance of YAG transparent ceramic sample after polishing is shown in Fig. 4. The optical transmittance of the sample is $80.2 \%$ at $1100 \mathrm{~nm}$. In order to investigate the microstructure of YAG transparent ceramic samples, the surface and fractured surface were observed in SEM equipment. As shown in Fig. 5(a), an SEM micrograph of the polished surface, there are nearly no obvious pores in or between the grains. Besides, a fractured surface micrograph is shown in Fig. 5(b). We can find that the grain boundaries and the triple junctions were clean and there were no secondary 


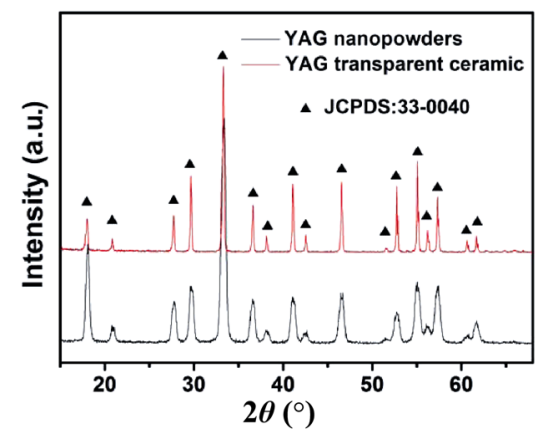

Fig. 3 XRD patterns of YAG powders and transparent ceramic samples.

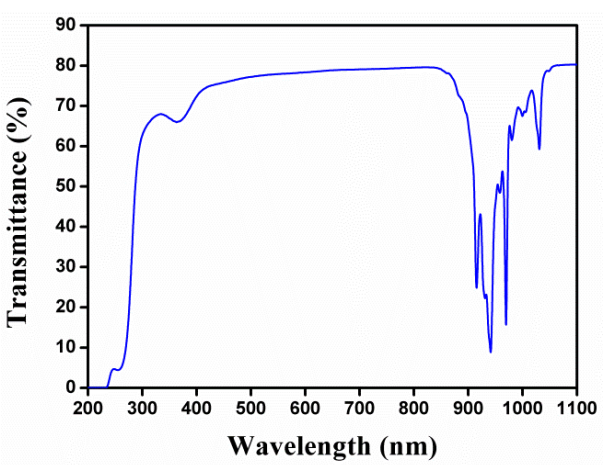

Fig. 4 Transmittance of YAG transparent ceramic specimen.

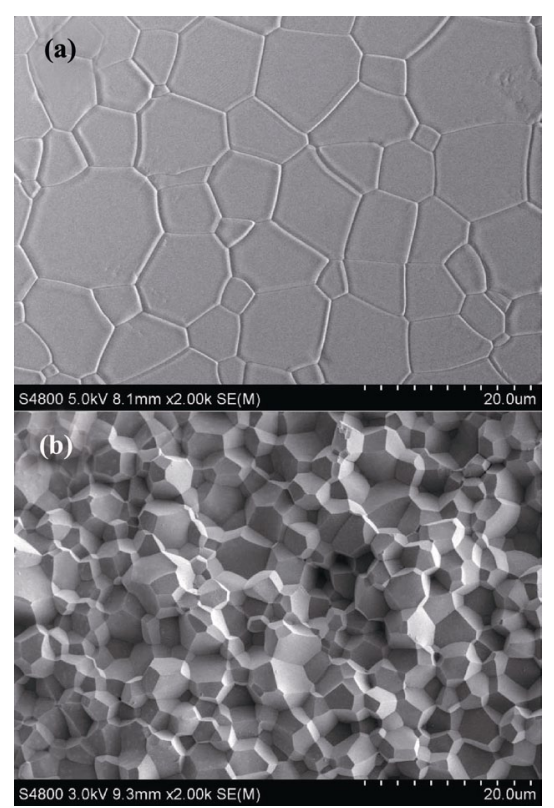

Fig. 5 SEM micrographs of the polished surface (a) and fracture surface (b) of YAG transparent ceramic sample.

phases. As mentioned before, the average grain size $G$ is an important parameter in our model. In order to obtain precise statistical distribution information of YAG ceramic grain size, the crystal orientation on the polished surface was characterized by electron backscatter diffraction method. In Fig. 6(b), we can find the EBSD orientation map of YAG sample which

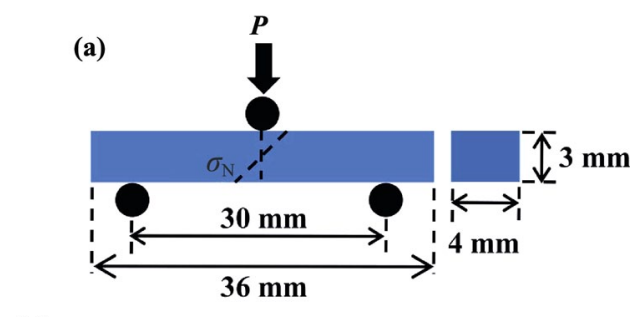

(b)

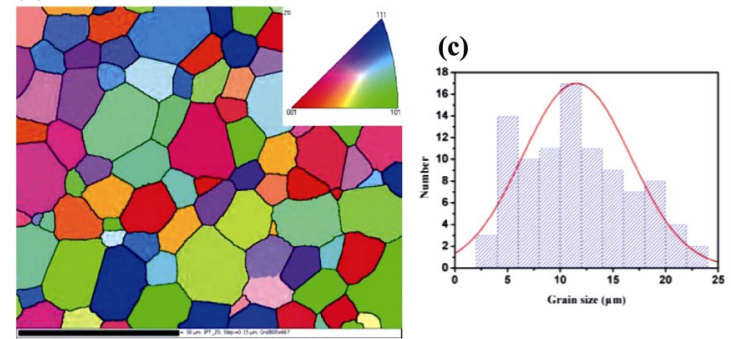

Fig. 6 (a) A diagrammatic sketch of three-point bending test, (b) EBSD orientation map, and (c) grain size distribution of YAG transparent ceramic specimen.

clearly exhibited the size of every grain in an area with dimension $125 \mu \mathrm{m} \times 12 \mathrm{fm}$. Besides, the grain size distribution with average grain size $G=12.4 \mu \mathrm{m}$ can also be found in Fig. 6(c). This distribution follows an accurate normal distribution.

As shown in Eq. (2), the tensile strength $\sigma_{\mathrm{y}}$ is equal to the fracture strength $\sigma_{\mathrm{N}}$ when the surfaces of specimens are perfect. Thus, before bending tests all of the YAG beam specimens with size $3 \mathrm{~mm} \times$ $4 \mathrm{~mm} \times 36 \mathrm{~mm}$ shown in Fig. 6(a) were polished carefully using $0.1 \mu \mathrm{m}$ diamond polishing paste. However, even highly polished surfaces maintain non-negligible roughness at small scales, and the defects or shallow surface cracks inevitably emerge on the surfaces of testing specimens. In order to investigate the dimension of defects randomly distributing on the surface of specimens, the AFM equipment was employed to observe the surface morphology. Figure 7 shows the photo (a) and the surface morphology (b) of the polished YAG beam specimens. We can see that the surface roughness of YAG specimens is about $19 \mathrm{~nm}$. Significantly, after carefully polishing the sizes of defects and shallow cracks on the sample surfaces were very small. Thus, the sizes of shallow surface cracks or surface defects on the bending YAG specimens were able to be treated as the average surface roughness of $19 \mathrm{~nm}$. Then, the average fracture strength of YAG specimens at room temperature was measured as 249 MPa. Let's look back to Eq. (5). The relationship between the elastic modulus of YAG ceramic and temperature must be identified in order to calculate the fracture toughness at different temperatures. As shown in Fig. 8, the elastic modulus of YAG was decreased 
YAG transparent ceran (a)

YAG transparent ceramics

YAG transparent ceramics

YAG transparent ceramics

YAG transparent ceramics

YAG transparent ceramics

(b)
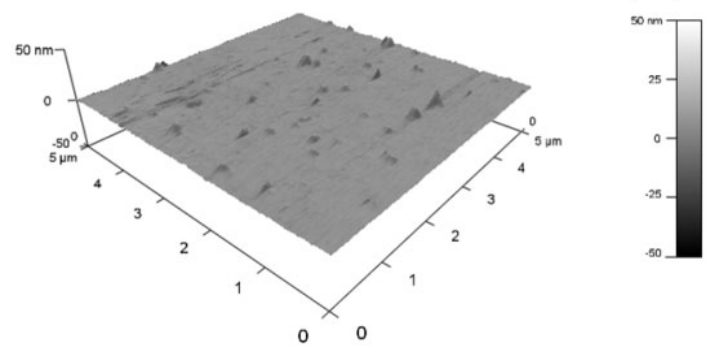

Fig. 7 (a) Photo and (b) surface morphology of YAG transparent ceramic specimens carried out bending fracture test.

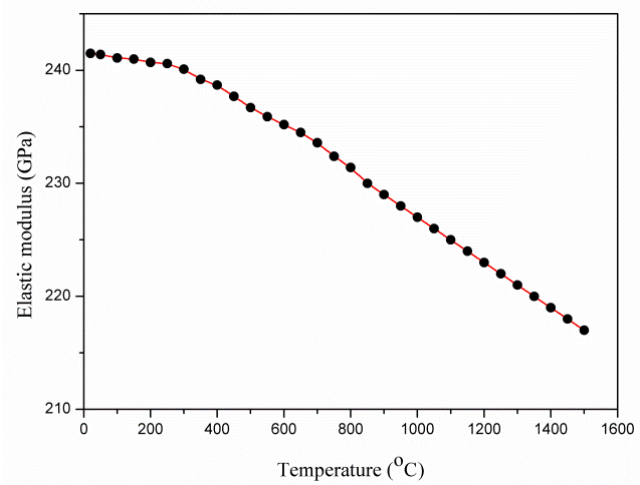

Fig. 8 Elastic modulus of YAG transparent ceramic as a function of temperature from room temperature $\left(26{ }^{\circ} \mathrm{C}\right)$ to $1600{ }^{\circ} \mathrm{C}$.

with increasing temperature from room temperature of $26{ }^{\circ} \mathrm{C}$ to $1600{ }^{\circ} \mathrm{C}$. This is coincident with our general understanding of the relationship between elastic modulus and temperature.

As mentioned before, we can calculate the fracture toughness using the bending fracture strength from Eq. (5). As shown in Fig. 9, the calculated fracture toughness of YAG transparent ceramic as a function of temperature from room temperature $\left(26{ }^{\circ} \mathrm{C}\right)$ to $1600{ }^{\circ} \mathrm{C}$ can be observed. For comparison, the fracture toughness values of YAG transparent ceramic measured by the conventional methods, such as SEPB and IF were also exhibited. Specifically, Boniecki et al. [52] using the SEPB method exhibited in the bottom left corner of

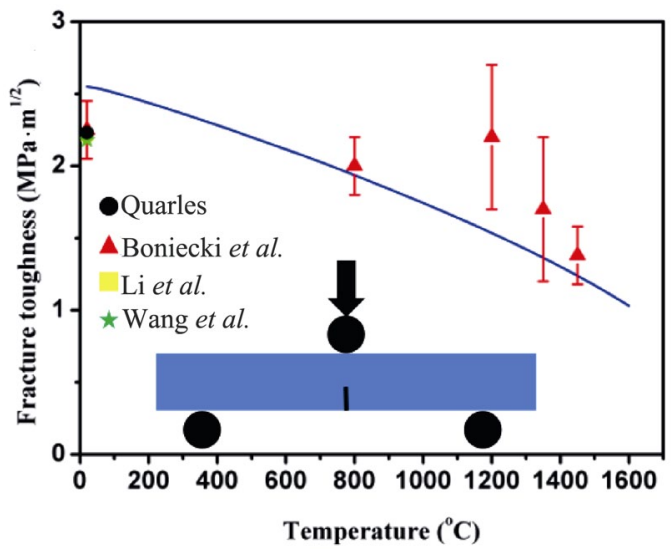

Fig. 9 Calculated and experimental values of fracture toughness of YAG transparent ceramic.

Fig. 9 investigating the fracture toughness of YAG transparent ceramic $(G=11 \mu \mathrm{m})$ at different temperature conditions. In their experiment, notches were firstly incised in the middle of the samples along the height using a circular saw with a width of $0.025 \mathrm{~mm}$. Then a blade was used to cut the sawing circular notches for machining the sharp pre-crack.

As shown in Fig. 9 we can see most of the fracture toughness values measured by the SEPB were slightly larger than our results calculated by Eq. (5) due to the notch passivation effect. Because a perfectly sharp pre-crack on the bending beam specimen is almost impossible. Besides, Li et al. [53] $(G=15 \mu \mathrm{m})$, Quarles [54] $(G=10 \mu \mathrm{m})$, and Wang et al. [55] ( $G=$ $12.4 \mu \mathrm{m})$ also obtained the fracture toughness of YAG transparent ceramics at room temperature using IF method. Generally speaking, fracture toughness values measured by the IF method are considered less accurate than those obtained by means of macroscopic tests [56,57]. The $K_{\mathrm{IC}}$ values, 2.21, 2.18, and 2.23 $\mathrm{MPa} \cdot \mathrm{m}^{1 / 2}$, obtained by Li et al., Quarles, and Wang et $a l$. respectively are less than our calculating results. So far the fracture toughness of YAG as a function of temperature can be well predicated by our methodology.

\section{Conclusions}

In summary, a new methodology was proposed to test the fracture toughness of YAG transparent ceramics. In this model, the fracture toughness, as a material-specific property, can be bridged with tensile strength treated as a physical property or material constant. Using this method, a suitable size larger than the inherent defects of ceramic samples and the 
creation of atomically sharp pre-cracks on the surface of ceramic specimens were able to be ignored. Besides, the fracture of ceramic can be described as the equivalence between the release of elastic storage energy and surface energy associated with the new fracture surface. From thermodynamics theory, the system's internal energy includes the kinetic energy of atomic motion and the potential energy between atoms in the system. Finally, the fracture toughness at different temperatures can also be calculated by this simple quantitative relationship. In order to confirm the validity of this model, the decreasing fracture toughness of YAG transparent ceramic with increasing temperature was predicted and coincided with the experimental results.

\section{Acknowledgements}

This work is supported by the National Natural Science Foundation of China (Grant Nos. 11327801, 11802042, and 11572057), the NSAF (Grant No. U1830136), Key Project of Education Department of Sichuan Province (Grant 15ZA0229), and the Sichuan Science and Technology Program (Grant No. 2017RZ0065).

\section{References}

[1] Goldstein A, Krell A. Transparent ceramics at 50: Progress made and further prospects. J Am Ceram Soc 2016, 99: 3173-3197.

[2] Upasani M. Synthesis of $\mathrm{Y}_{3} \mathrm{Al}_{5} \mathrm{O}_{12}$ : $\mathrm{Eu}$ and $\mathrm{Y}_{3} \mathrm{Al}_{5} \mathrm{O}_{12}: \mathrm{Eu}, \mathrm{Si}$ phosphors by combustion method: Comparative investigations on the structural and spectral properties. J Adv Ceram 2016, 5: 344-355.

[3] Kim W, Villalobos G, Baker C, et al. Overview of transparent optical ceramics for high-energy lasers at NRL. Appl Opt 2015, 54: F210-F221.

[4] Li J, Pan YB, Zeng YP, et al. The history, development, and future prospects for laser ceramics: A review. Int $J$ Refract Met Hard Mater 2013, 39: 44-52.

[5] Zhang W, Lu TC, Ma BY, et al. Improvement of optical properties of $\mathrm{Nd}$ YYAG transparent ceramics by post-annealing and post hot isostatic pressing. Opt Mater 2013, 35: 2405-2410.

[6] $\mathrm{Hu}$ GL, Ramesh KT, Cao BY, et al. The compressive failure of aluminum nitride considered as a model advanced ceramic. J Mech Phys Solids 2011, 59: 1076-1093.

[7] Supancic P. Mechanical stability of $\mathrm{BaTiO}_{3}$-based PTC thermistor components: Experimental investigation and theoretical modelling. J Eur Ceram Soc 2000, 20: 20092024.

[8] Deluca M, Bermejo R, Pletz M, et al. Strength and fracture analysis of silicon-based components for embedding. $J$ Eur Ceram Soc 2011, 31: 549-558.

[9] Boniecki M, Librant Z, Wajler A, et al. Fracture toughness, strength and creep of transparent ceramics at high temperature. Ceram Int 2012, 38: 4517-4524.

[10] Jiménez-Melendo M, Haneda H, Nozawa H. Ytterbium cation diffusion in yttrium aluminum garnet (YAG)implications for creep mechanisms. J Am Ceram Soc 2004, 84: 2356-2360.

[11] Lawn BR. Fracture of Brittle Solids. Cambridge University Press, 1993.

[12] Yao WL, Liu J, Holland TB, et al. Grain size dependence of fracture toughness for fine grained alumina. Scripta Mater 2011, 65: 143-146.

[13] Zhu XK, Joyce JA. Review of fracture toughness (G, K, J, CTOD, CTOA) testing and standardization. Eng Fract Mech 2012, 85: 1-46.

[14] Danzer R, Lube T, Supancic P, et al. Fracture of ceramics. Adv Eng Mater 2008, 10: 275-298.

[15] Danzer R. On the relationship between ceramic strength and the requirements for mechanical design. $J$ Eur Ceram Soc 2014, 34: 3435-3460.

[16] Soderholm KJ. Review of the fracture toughness approach. Dent Mater 2010, 26: e63-e77.

[17] Belli R, Wendler M, de Ligny D, et al. Chairside CAD/CAM materials. Part 1: Measurement of elastic constants and microstructural characterization. Dent Mater 2017, 33: 84-98.

[18] Cesar PF, Bona AD, Scherrer SS, et al. ADM guidanceCeramics: Fracture toughness testing and method selection. Dent Mater 2017, 33: 575-584.

[19] Miyazaki H, Yoshizawa Y. A reinvestigation of the validity of the indentation fracture (IF) method as applied to ceramics. J Eur Ceram Soc 2017, 37: 4437-4441.

[20] Miyazaki H, Yoshizawa YI, Hirao K, et al. Evaluation of fracture toughness of ceramic thin plates through modified single edge-precracked plate method. Scripta Mater 2015, 103: 34-36.

[21] Moradkhani A, Baharvandi H, Tajdari $\mathrm{M}$, et al. Determination of fracture toughness using the area of micro-crack tracks left in brittle materials by Vickers indentation test. $J A d v$ Ceram 2013, 2: 87-102.

[22] Launey ME, Ritchie RO. On the fracture toughness of advanced materials. Adv Mater 2009, 21: 2103-2110.

[23] Roberts RJ, Rowe RC, York P. The measurement of the critical stress intensity factor $\left(K_{\mathrm{IC}}\right)$ of pharmaceutical powders using three point single edge notched beam (SENB) testing. Int J Pharm 1993, 91: 173-182.

[24] Anstis GR, Chantikul P, Lawn BR, et al. A critical evaluation of indentation techniques for measuring fracture toughness: I, direct crack measurements. J Am Ceram Soc 1981, 64: 533-538.

[25] Quinn GD, Bradt RC. On the Vickers indentation fracture toughness test. J Am Ceram Soc 2007, 90: 673-680.

[26] Nose T, Fujii T. Evaluation of fracture toughness for ceramic materials by a single-edge-precracked-beam method. 
J Am Ceram Soc 1988, 71: 328-333.

[27] Quinn GD, Swab JJ, Motyka MJ. Fracture toughness of a toughened silicon nitride by ASTM C 1421. J Am Ceram Soc 2003, 86: 1043-1045.

[28] Fett T. Notch effects in determination of fracture toughness and compliance. Int J Fract 1995, 72: R27-R30.

[29] Kübler, J. Fracture toughness of ceramics using the SEVNB method: Preliminary results. In Proceedings of the 21st Annual Conference on Composites, Advanced Ceramics, Materials, and Structures-B: Ceramic Engineering and Science Proceedings, 2008.

[30] Awaji H, Sakaida Y. V-notch technique for single-edge notched beam and chevron notch methods. J Am Ceram Soc 1990, 73: 3522-3523.

[31] Calderon-Moreno JM, Popa M. Fracture toughness anisotropy by indentation and SEVNB on tetragonal PZT polycrystals. Mat Sci Eng A 2001, 319-321: 692-696.

[32] Gogotsi GA. Fracture toughness of ceramics and ceramic composites. Ceram Int 2003, 29: 777-784.

[33] Lemaitre P, Piller R. Comparison of the fracture toughness of alumina measured by three different methods. $J$ Mater Sci Lett 1988, 7: 772-774.

[34] Picard D, Leguillon D, Putot C. A method to estimate the influence of the notch-root radius on the fracture toughness measurement of ceramics. J Eur Ceram Soc 2006, 26: 1421-1427.

[35] Niihara K. A fracture mechanics analysis of indentationinduced Palmqvist crack in ceramics. J Mater Sci Lett 1983, 2: 221-223.

[36] Fett T. Estimated stress intensity factors for semi-elliptical cracks in front of narrow circular notches. Eng Fract Mech 1999, 64: 357-362.

[37] Damani R, Gstrein R, Danzer R. Critical notch-root radius effect in SENB-S fracture toughness testing. $J$ Eur Ceram Soc 1996, 16: 695-702.

[38] Fett T. Influence of a finite notch root radius on fracture toughness. J Eur Ceram Soc 2005, 25: 543-547.

[39] Nishida T, Hanaki Y, Pezzotti G. Effect of notch-root radius on the fracture toughness of a fine-grained alumina. J Am Ceram Soc 1994, 77: 606-608.

[40] Fischer H, Waindich A, Telle R. Influence of preparation of ceramic SEVNB specimens on fracture toughness testing results. Dent Mater 2008, 24: 618-622.

[41] Carlton HD, Elmer JW, Freeman DC, et al. Laser notching ceramics for reliable fracture toughness testing. $J$ Eur Ceram Soc 2016, 36: 227-234.

[42] Quinn JB, Lloyd IK. Comparison of methods to determine the fracture toughness of three glass-ceramics at elevated temperatures. J Am Ceram Soc 2000, 83: 3070-3076.

[43] Rouxel T, Yoshida S. The fracture toughness of inorganic glasses. J Am Ceram Soc 2017, 100: 4374-4396.

[44] Marshall DB, Cook RF, Padture NP, et al. The compelling case for indentation as a functional exploratory and characterization tool. J Am Ceram Soc 2015, 98: 2671-2680.

[45] Kruzic JJ, Kim DK, Koester KJ, et al. Indentation techniques for evaluating the fracture toughness of biomaterials and hard tissues. J Mech Behav Biomed Mater 2009, 2: 384-395.

[46] Scherrer SS, Lohbauer U, Della Bona A, et al. ADM guidance - Ceramics: Guidance to the use of fractography in failure analysis of brittle materials. Dent Mater 2017, 33: 599-620.

[47] Zhang CG, Hu XZ, Sercombe T, et al. Prediction of ceramic fracture with normal distribution pertinent to grain size. Acta Mater 2018, 145: 41-48.

[48] $\mathrm{Hu}$ XZ, Wittmann F. Size effect on toughness induced by crack close to free surface. Eng Fract Mech 2000, 65: 209-221.

[49] Deng Y, Li WG, Shao JX, et al. A novel theoretical model to predict the temperature-dependent fracture strength of ceramic materials. J Eur Ceram Soc 2017, 37: 5071-5077.

[50] Kimoto H, Usami S, Miyata H. Flaw size dependence in fracture stress of glass and polycrystalline ceramics. JSMET 1985, 51: 2482-2488.

[51] Zhao W, Rao PG, Ling ZY. A new method for the preparation of ultra-sharp V-notches to measure fracture toughness in ceramics. J Eur Ceram Soc 2014, 34: 4059-4062.

[52] Boniecki M, Librant Z, Wajler A, et al. Fracture toughness, strength and creep of transparent ceramics at high temperature. Ceram Int 2012, 38: 4517-4524.

[53] Li J, Wu YS, Pan YB, et al. Fabrication, microstructure and properties of highly transparent Nd:YAG laser ceramics. Opt Mater 2008, 31: 6-17.

[54] Quarles GJ. State of art of polycrystalline oxide laser gain materials. In: Proceedings of the 46th Army Sagamore Materials Research Conference, 2005: 9-12.

[55] Wang HM, Huang ZY, Jiang JS, et al. Unique mechanical properties of nano-grained YAG transparent ceramics compared with coarse-grained partners. Mater Des 2016, 105: 9-15.

[56] Quinn GD, Bradt RC. On the Vickers indentation fracture toughness test. J Am Ceram Soc 2007, 90: 673-680.

[57] Zhang TH, Feng YH, Yang R, et al. A method to determine fracture toughness using cube-corner indentation. Scripta Mater 2010, 62: 199-201.

Open Access This article is licensed under a Creative Commons Attribution 4.0 International License, which permits use, sharing, adaptation, distribution and reproduction in any medium or format, as long as you give appropriate credit to the original author(s) and the source, provide a link to the Creative Commons licence, and indicate if changes were made.

The images or other third party material in this article are included in the article's Creative Commons licence, unless indicated otherwise in a credit line to the material. If material is not included in the article's Creative Commons licence and your intended use is not permitted by statutory regulation or exceeds the permitted use, you will need to obtain permission directly from the copyright holder.

To view a copy of this licence, visit http://creativecommons.org/licenses/by/4.0/. 